\title{
ATOMIC LEVEL CHARACTERIZATION OF PRECIPITATION IN ALLOY 718
}

\author{
M. K. Miller and S. S. Babu \\ Metals and Ceramics Division, \\ Oak Ridge National Laboratory, \\ P. O. Box 2008, \\ Oak Ridge, TN 37831-6376, USA.
}

\begin{abstract}
Alloy 718 derives its good mechanical properties from a fine dispersion of ordered precipitates in a face centered cubic matrix. However, the precise nature of these precipitates has only been resolved recently through atomic level characterization of the compositions of these precipitates in a three-dimensional atom probe. Atom probe tomography has revealed that these fine $(<\sim 20 \mathrm{~nm}$ diameter) precipitates generally consist of two distinct types of regions that are enriched either in niobium or in aluminum and titanium that are characteristic of the $\gamma^{\prime \prime}$ and $\gamma^{\prime}$ phases, respectively. Reasonable agreement may be achieved between atom probe measurements and thermodynamic predictions of the compositions of these phases when additional microstructural information is taken into account and absent phases are suppressed in thermodynamic calculations.
\end{abstract}




\section{Introduction}

Niobium-containing Alloy 718 is strengthened by a combination of $\mathrm{DO}_{22}$-ordered $\mathrm{Ni}_{3}(\mathrm{Nb}, \mathrm{Ti}) \gamma^{\prime \prime}$ and $\mathrm{Ll}_{2}$-ordered $\mathrm{Ni}_{3}(\mathrm{Al}, \mathrm{Ti}, \mathrm{Nb}) \gamma^{\prime}$ phases in a face centered cubic $\gamma$ matrix [1-5]. Both the $\mathrm{DO}_{22}{ }^{-}$ ordered and $\mathrm{Ll}_{2}$-ordered crystal structures are derivatives of the face centered cubic structure. The $\mathrm{DO}_{22}$-ordered structure can be described as an $\mathrm{Ll}_{2}$-ordered structure with an a $\left[\frac{1}{2} \frac{1}{2} 0\right]$ displacement every other 001 plane thereby converting a cubic structure into a tetragonal one. The compositions of these two ordered phases may both be described as $\mathrm{Ni}_{3}(\mathrm{Al}, \mathrm{Ti}, \mathrm{Nb})$ with varying levels of aluminum, titanium and niobium. Since these ordered phases form in different temperature ranges, it is possible to tailor the quantity, size and composition of the phases present by careful control of the heat treatment and the composition of the alloy. Thermodynamic calculations may be used in this alloy design process to rapidly predict the quantity and compositions of the co-existing phases present [6]. This alloy design process may also be used to ascertain if it is possible to suppress deleterious phases such as the $\sigma$ or Laves phases. In addition, this approach may be used to refine the Alloy 718 specification in order to make more effective use of the alloying elements as their partitioning behavior is calculated. In order to adopt this approach, the accuracy of these thermodynamic predictions must be evaluated on real alloys over a range of alloy compositions and heat treatments.

Atom probe tomography (APT) is able to measure the partitioning and concentrations of all the alloying elements in the phases present in these complex systems [7-9]. The compositions of small volumes are estimated from the numbers of atoms of each solute in that volume. Previous atom probe tomography characterizations of Alloy 718 [10-13] revealed that the secondary or fine $(<\sim 20 \mathrm{~nm}$ diameter $)$ precipitates consisted of two distinct types of regions enriched in either niobium or in aluminum and titanium that are characteristic of the $\gamma^{\prime \prime}$ and $\gamma^{\prime}$ phases, respectively.

In this paper, a comparison is made of the compositions of the phases present in Alloy 718 as predicted by thermodynamic calculations and measured by atom probe tomography. This study complements a previous comparison of the compositions of phases present in an Alloy 718 ( $\mathrm{Ni}$ 21.8 at. $\% \mathrm{Cr}, 20.3 \% \mathrm{Fe}, 3.2 \% \mathrm{Nb}, 1.81 \% \mathrm{Mo}, 1.15 \% \mathrm{Ti}, 0.96 \% \mathrm{Al}, 0.26 \% \mathrm{Co}$ and $0.26 \% \mathrm{C}$ ) with a different multistep heat treatment as predicted by thermodynamic calculations and measured by atom probe tomography [12-13].

\section{Experimental}

\section{Material and Heat Treatments}

The nominal composition of the commercial Alloy 718 used in this study was Ni- 21.5 at. \% Fe, $19.6 \% \mathrm{Cr}, 0.31 \% \mathrm{Co}, 1.76 \% \mathrm{Mo}, 3.24 \% \mathrm{Nb}, 1.18 \% \mathrm{Ti}, 1.27 \% \mathrm{Al}$ and $0.19 \% \mathrm{C}$ (Ni- 20.7 wt $\%$ $\mathrm{Fe}, 17.6 \% \mathrm{Cr}, 0.32 \% \mathrm{Co}, 2.92 \% \mathrm{Mo}, 5.21 \% \mathrm{Nb}, 1.05 \% \mathrm{Ti}, 0.55 \% \mathrm{Al}$, and $0.04 \% \mathrm{C}$ ). All compositions presented in this paper are given in atomic percent.

The material was given a multistep heat treatment of $1 \mathrm{~h}$ at $1093^{\circ} \mathrm{C}, 8 \mathrm{~h}$ at $718^{\circ} \mathrm{C}$, a slow cool at a rate of $55^{\circ} \mathrm{C} / \mathrm{h}$ to $621^{\circ} \mathrm{C}, 8 \mathrm{~h}$ at $621^{\circ} \mathrm{C}$ and an air cool to room temperature. The microstructural characterizations were performed after the $8 \mathrm{~h}$ at $718^{\circ} \mathrm{C}$ step and after the complete multi-step heat treatment. In this paper, these two conditions are referred to as the 718 and $621^{\circ} \mathrm{C}$ heat treatments, respectively. 
Previous transmission electron microscopy characterization of this alloy after these heat treatments revealed a few coarse $(1-2 \mu \mathrm{m})$ MC-type inclusions. No $\sigma$ phase precipitates were observed. The relatively low chromium level of this Alloy 718 may be significant in suppressing the formation of $\delta$ and Laves phases. No $\delta$, Laves or NbC precipitates were detected at the grain boundaries. In addition, a uniform distribution of $\sim 5-13 \mathrm{~nm}$ precipitates was observed in the $\gamma$ matrix. Similar size estimates were also obtained from field ion images, as shown in Fig. 1. No significant difference in the microstructure was noted after the $8 \mathrm{~h}$ at $718^{\circ} \mathrm{C}$ step and after subsequent stages of the full heat treatment. No other intragranular phases, such as the chromium-enriched $\delta$ and Laves, were observed.

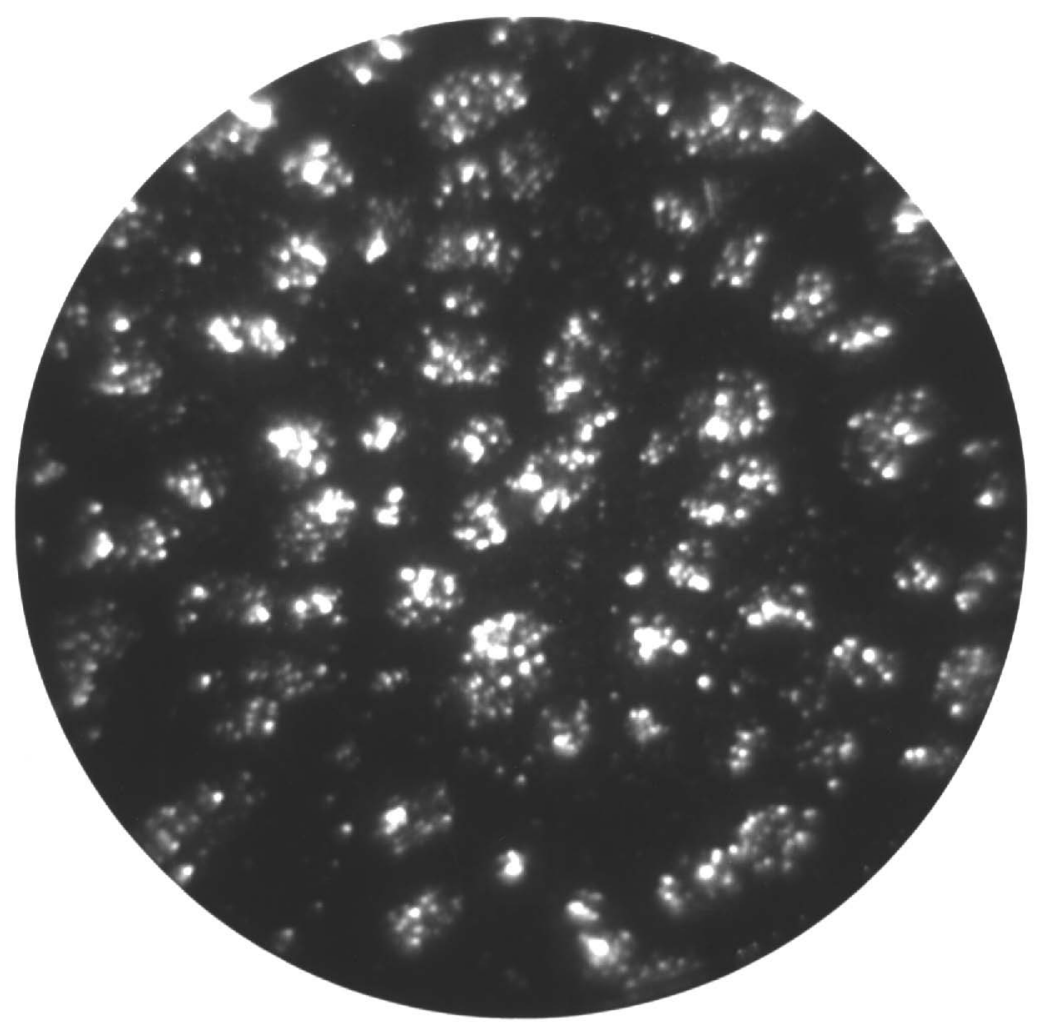

Figure 1. Field ion micrograph of the $\sim 5-13 \mathrm{~nm}$ intragranular precipitates observed in Alloy 718 after a multistep heat treatment of $1 \mathrm{~h}$ at $1093^{\circ} \mathrm{C}, 8 \mathrm{~h}$ at $718^{\circ} \mathrm{C}$, a slow cool at a rate of $55^{\circ} \mathrm{C} / \mathrm{h}$ to $621^{\circ} \mathrm{C}, 8 \mathrm{~h}$ at $621^{\circ} \mathrm{C}$ and an air cool to room temperature.

\section{Atom Probe Tomography}

The compositions of the phases present in this superalloy were characterized in the Oak Ridge National Laboratory's (ORNL) energy-compensated three-dimensional atom probe (3DAP). This instrument permits the spatial coordinates and the elemental identity of the atoms in a small volume to be determined [9]. An atom map of a 2-nm-thick slice through the central region of an intragranular precipitate is shown in Fig. 2. In this representation, a color-coded sphere is used to represent the position of an individual atom. Composition profiles through two different precipitates are shown in Fig. 3. The dual phase nature of these precipitates is evident from the different composition regions within the precipitate envelope corresponding to $\gamma^{\prime}$ and $\gamma^{\prime \prime}$ phase regions. The compositions were estimated from averages of several selected volumes in different 
precipitates or $\gamma$ phase regions [9]. The identity of the phases was based on the measured compositions.
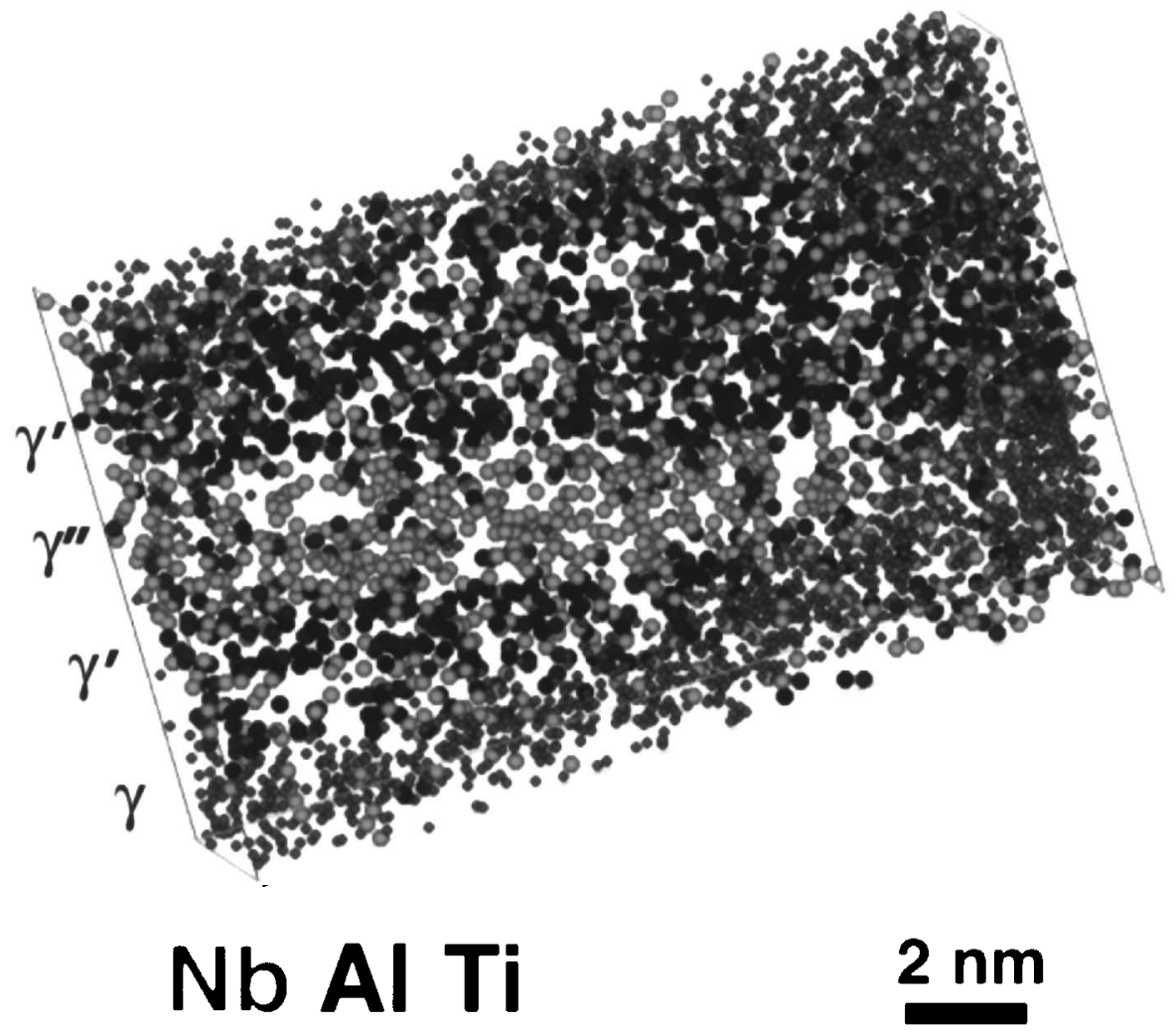

$2 \mathrm{~nm}$

Figure 2: Atom map of a 2-nm-thick slice through a precipitate in the $\gamma$ matrix showing the dual phase nature of the precipitate.
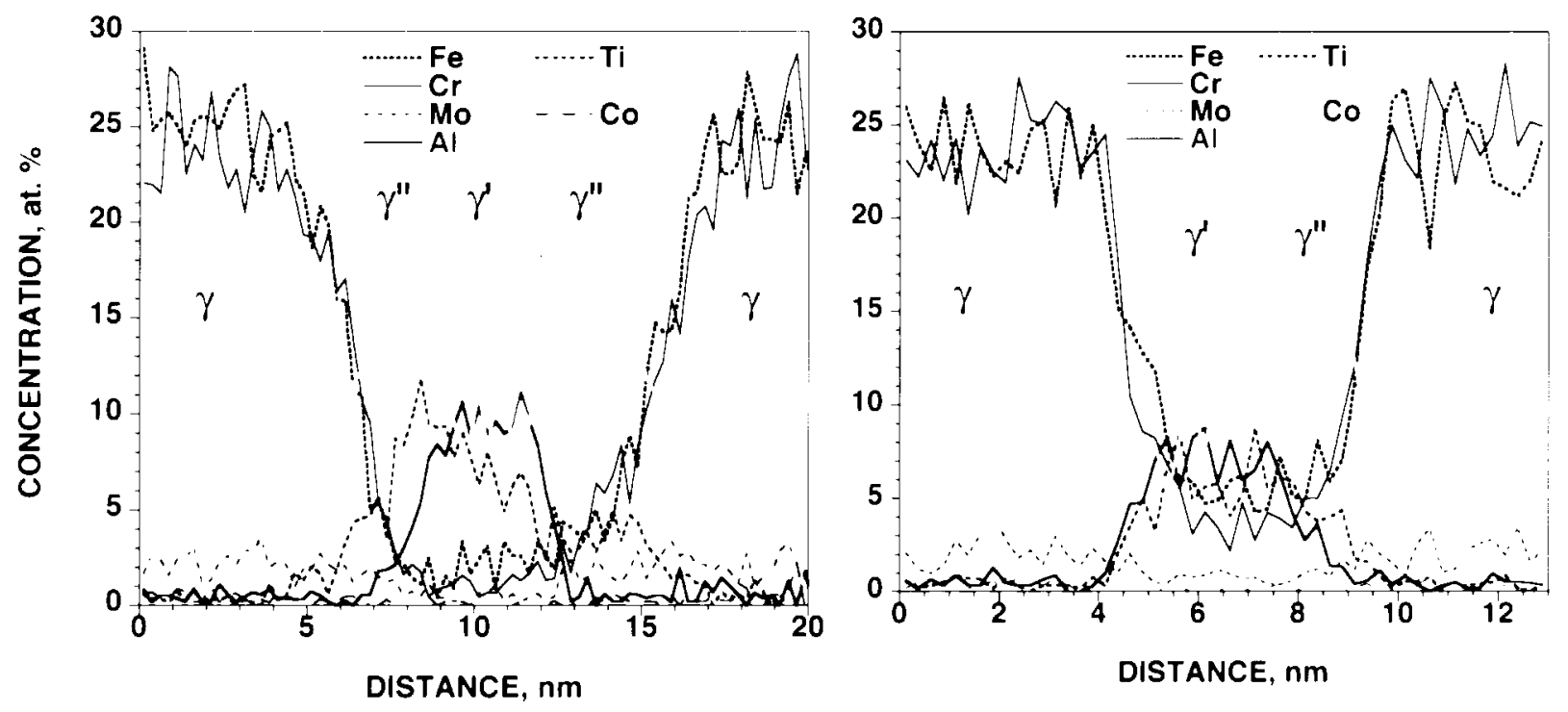

Figure 3. Composition profiles through the central regions of two intragadala precipitates showing their dual and triple region nature.

Small bars were cut from bulk heat-treated materials with a diamond saw and then electropolished into needle-shaped specimens with two electrolytes: A) $25 \%$ perchloric acid in glacial acetic acid and B) $2 \%$ perchloric acid in 2-butoxyethanol [9]. A specimen temperature of 
$60 \mathrm{~K}$, a pulse fraction of $20 \%$, and a pulse repetition rate of $1500 \mathrm{~Hz}$ was used for all atom probe analyses.

\section{Thermodynamic Calculations}

The equilibrium compositions and the relative amounts of phases present in Alloy 718 at different temperatures were calculated with the use of Thermocalc ${ }^{\mathrm{TM}}$ version $\mathrm{M}$ and a commercial 12 element $\mathrm{Ni}-\mathrm{Fe}$ database [15]. The phases considered in the calculation were face centered cubic $\gamma, \mathrm{L1}_{2}$-ordered $\gamma^{\prime}, \mathrm{DO}_{22}$-ordered $\gamma^{\prime \prime}, \sigma$, Laves, $\mathrm{MC}, \mathrm{M}_{6} \mathrm{C}, \mathrm{M}_{23} \mathrm{C}_{6}, \mathrm{M}_{7} \mathrm{C}_{3}$ and liquid. It was necessary to suppress the orthorhombic $\mathrm{Ni}_{3} \mathrm{Nb} \delta$ phase from the calculations due to its interference with the $\gamma$ " phase.

\section{Thermodynamic Predictions}

The thermodynamic predictions of the equilibrium phase compositions and their molar fractions at 1093,718 and $621^{\circ} \mathrm{C}$ are shown in Table I. At $1093^{\circ} \mathrm{C}$, the only phases predicted to be present were the $\gamma$ matrix and a small molar fraction $(0.39 \%)$ of $\mathrm{NbC}$. At 718 and $621^{\circ} \mathrm{C}, \gamma^{\prime \prime}, \gamma^{\prime}$ and $\sigma$ phases were also predicted to be present. A small molar fraction $(0.93 \%)$ of $\mathrm{Cr}_{23} \mathrm{C}_{6}$ was also predicted to be present at $621^{\circ} \mathrm{C}$. These calculations predicted that iron, chromium, cobalt and molybdenum partition preferentially to the $\gamma$ matrix, niobium and titanium partition to the $\gamma^{\prime \prime}$ phase and approximately equal levels of aluminum, titanium and niobium partition to the $\gamma^{\prime}$ phase. Niobium, titanium and carbon were predicted to be present in a small molar fraction of $\mathrm{NbC}$ at both 1093 and $718^{\circ} \mathrm{C}$ and chromium, molybdenum and carbon to be present in $\mathrm{Cr}_{23} \mathrm{C}_{6}$ at $621^{\circ} \mathrm{C}$. Chromium, iron, nickel, and molybdenum were also predicted to be present in a small molar fraction of $\sigma$ phase at both 718 and $621^{\circ} \mathrm{C}$. Compared to those at $718^{\circ} \mathrm{C}$, the predictions at $621^{\circ} \mathrm{C}$ showed that the molar fractions of the $\gamma^{\prime \prime}$ and $\gamma^{\prime}$ phases increased and the $\gamma$ matrix decreased. The iron and chromium levels decreased in the $\gamma^{\prime \prime}$ and $\gamma^{\prime}$ phases and increased in the $\gamma$ phase. Similarly, the niobium, aluminum and titanium levels decreased in the $\gamma$ phase, and the niobium level increased and the titanium level decreased in the $\gamma^{\prime \prime}$ phase.

As the ( $\mathrm{Cr}-\mathrm{Fe}-\mathrm{Ni}-\mathrm{Mo}) \sigma$ phase was not observed experimentally, a second set of predictions was also calculated with the $\sigma$ phase suppressed. When the $\sigma$ phase was suppressed, the Laves phase was predicted to form instead. As the Laves phase was not observed experimentally, it was also suppressed in the second set of predictions. The predicted phase compositions and molar fractions are given in Table II. When both the $\sigma$ and Laves phases were suppressed in the calculations, the molar fractions of the Cr-enriched $\gamma$ matrix increased from $78.07 \%$ to to $79.90 \%$ at $718^{\circ} \mathrm{C}$ and from $72.09 \%$ to $76.72 \%$ at $621^{\circ} \mathrm{C}$. In addition, the chromium and molybdenum levels in the $\gamma$ matrix increased from $23.75 \%$ to $24.36 \% \mathrm{Cr}$ and $1.82 \%$ to $2.11 \%$ Mo at $718^{\circ} \mathrm{C}$ and from $22.86 \%$ to $24.60 \% \mathrm{Cr}$ and $1.37 \%$ to $2.07 \%$ Mo at $621^{\circ} \mathrm{C}$. A trace amount $(0.005 \%)$ of the $\mathrm{Cr}$-rich $\mathrm{Cr}_{23} \mathrm{C}_{6}$ was also predicted to form at $718^{\circ} \mathrm{C}$.

\section{Atom Probe Tomography Composition Estimates}

The phase compositions that were determined by atom probe tomography are summarized in Table III. The partitioning of the alloying elements was found to be in agreement with the thermodynamic predictions in that iron and chromium partition to the $\gamma$ matrix, niobium and titanium partition to the $\gamma^{\prime \prime}$ phase, and aluminum, titanium and niobium partition to the $\gamma^{\prime}$ phase. In addition, there was general agreement between the measured and predicted compositions. Some minor differences were observed between the atom probe tomography measurements and the equilibrium compositions predicted by thermodynamic calculations. The niobium level in 


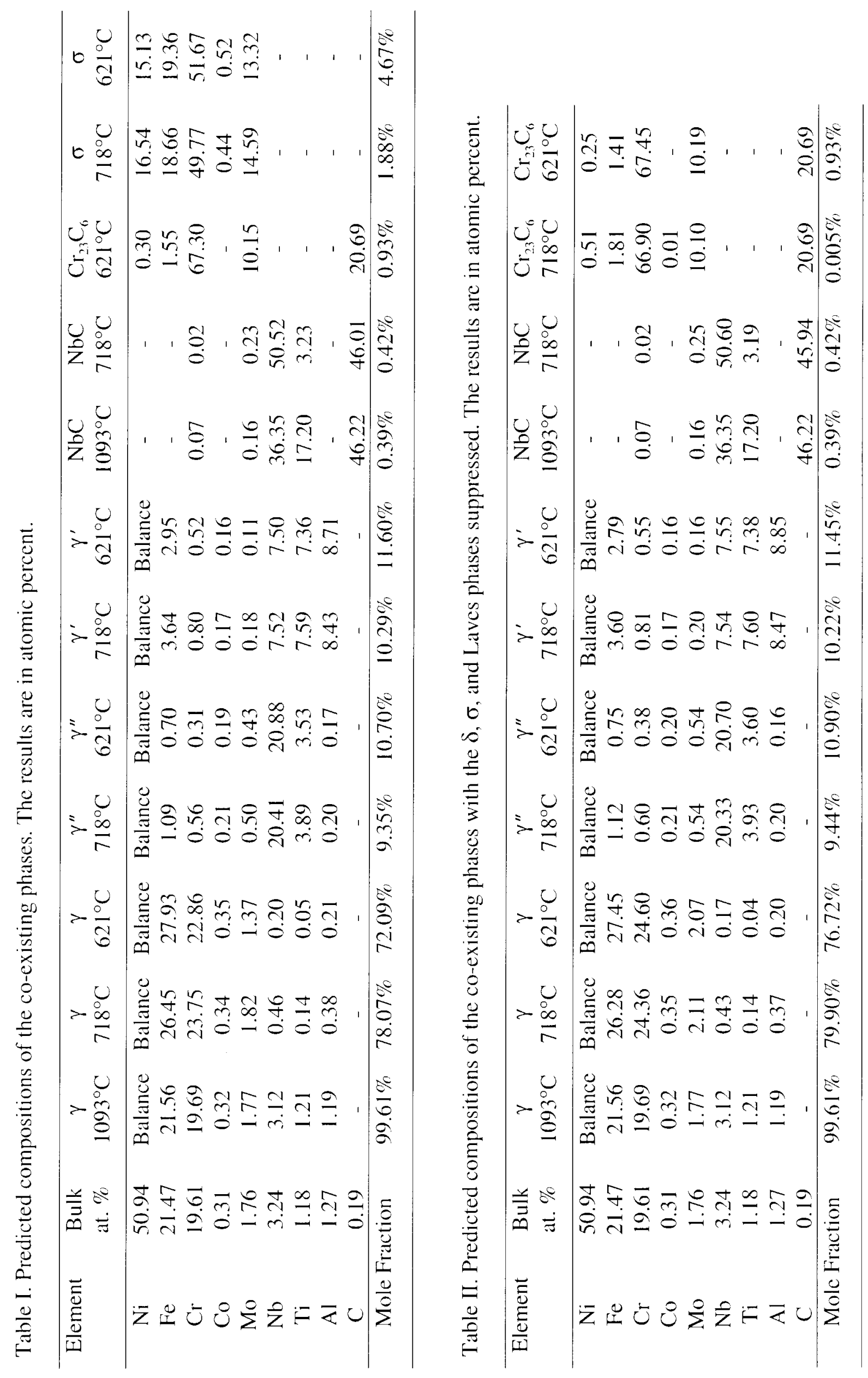


the $\gamma$ matrix was slightly higher than the predictions. The iron, chromium, molybdenum and titanium levels were slightly higher than predicted in the $\gamma^{\prime \prime}$ phase. The iron level was lower and the molybdenum level was higher than predicted in the $\gamma^{\prime}$ phase. Some of these small differences may be due to the compositions of the phases not attaining equilibrium due to the multistep heat treatment and the relatively short times of the heat treatment.

Table III. Compositions of the phases as determined by atom probe tomography after the $718^{\circ} \mathrm{C}$ and $621{ }^{\circ} \mathrm{C}$ stages of the heat treatment. The balance of these compositions is nickel, the values are quoted in atomic percent and the errors are one standard deviation.

\begin{tabular}{ccc}
\hline Element & $718^{\circ} \mathrm{C}$ & $621^{\circ} \mathrm{C}$ \\
\hline $\mathrm{Fe}$ & $25.54 \pm 0.18$ & $26.92 \pm 0.17$ \\
$\mathrm{Cr}$ & $23.48 \pm 0.17$ & $25.25 \pm 0.17$ \\
$\mathrm{Co}$ & $0.38 \pm 0.02$ & $0.47 \pm 0.02$ \\
$\mathrm{Mo}$ & $2.13 \pm 0.05$ & $2.50 \pm 0.05$ \\
$\mathrm{Nb}$ & $1.59 \pm 0.04$ & $0.99 \pm 0.03$ \\
$\mathrm{Ti}$ & $0.47 \pm 0.02$ & $0.21 \pm 0.01$ \\
$\mathrm{Al}$ & $0.58 \pm 0.03$ & $0.34 \pm 0.02$ \\
\hline \multicolumn{3}{c}{} \\
$\mathrm{Fe}$ & $2.11 \pm 0.22$ & $1.73 \pm 0.20$ \\
$\mathrm{Cr}$ & $2.16 \pm 0.22$ & $1.93 \pm 0.22$ \\
$\mathrm{Co}$ & $0.05 \pm 0.03$ & $0.19 \pm 0.07$ \\
$\mathrm{Mo}$ & $1.30 \pm 0.17$ & $3.00 \pm 0.27$ \\
$\mathrm{Nb}$ & $20.07 \pm 0.68$ & $19.27 \pm 0.68$ \\
$\mathrm{Ti}$ & $5.59 \pm 0.36$ & $4.73 \pm 0.34$ \\
$\mathrm{Al}$ & $0.35 \pm 0.09$ & $0.44 \pm 0.10$ \\
\hline \multicolumn{3}{c}{$\gamma^{\prime \prime}$ phase } \\
\hline $\mathrm{Fe}$ & $2.00 \pm 0.13$ & $2.24 \pm 0.23$ \\
$\mathrm{Cr}$ & $0.79 \pm 0.08$ & $0.83 \pm 0.14$ \\
$\mathrm{Co}$ & $0.09 \pm 0.03$ & $0.10 \pm 0.05$ \\
$\mathrm{Mo}$ & $0.53 \pm 0.07$ & $1.38 \pm 0.18$ \\
$\mathrm{Nb}$ & $7.22 \pm 0.24$ & $7.54 \pm 0.43$ \\
$\mathrm{Ti}$ & $7.38 \pm 0.25$ & $8.24 \pm 0.44$ \\
$\mathrm{Al}$ & $9.11 \pm 0.27$ & $8.79 \pm 0.46$ \\
\hline & \\
\hline
\end{tabular}

\section{Conclusions}

Atom probe tomography has revealed that these fine $(<\sim 20 \mathrm{~nm}$ diameter) precipitates generally consist of two distinct types of regions that are enriched either in niobium or in aluminum and titanium that are characteristic of the $\gamma^{\prime \prime}$ and $\gamma^{\prime}$ phases, respectively. Reasonable agreement may be achieved between atom probe measurements and thermodynamic predictions of the compositions of these phases when additional microstructural information is taken into account and absent phases are suppressed in thermodynamic calculations. 


\section{Acknowledgements}

The authors would like to thank Dr. M. G. Burke of Bechtel Bettis Inc. for supplying the materials used in this investigation and K. F. Russell for her technical assistance. Research at the Oak Ridge National Laboratory SHaRE User Facility was sponsored by the Division of Materials Sciences and Engineering, U.S. Department of Energy, under contract DE-AC0500OR22725 with UT-Battelle, LLC.

\section{References}

1. Proc. Superalloy 718, June 1989, Pittsburgh PA, ed. E.A. Loria (Warrendale, PA: The Minerals, Metals and Materials Society, 1989).

2. M. G. Burke and M. K. Miller, "APFIM/TEM Characterization of Precipitation in Superalloy 718", J. de Physique, 50-C8 (1989), 395-400.

3. M. K. Miller and M. G. Burke, "Atom Probe Analysis of the Compositions of $\gamma$ ' and $\gamma$ " Intermetallic Phases in Nickel-based Superalloy 718", Proc. Alloy Phase Stability and Design, April 1990, San Francisco, CA, vol. 186, ed. G. M. Stocks, S. P. Pope and A. F. Giamei (Pittsburgh, PA: Materials Research Society, 1991), 223-228.

4. M. G. Burke and M. K. Miller, "Grain Boundary Intermetallic Phases in Alloy 718 ", Proc. Alloy Phase Stability and Design, April 1990, San Francisco, CA, vol. 186, ed. G. M. Stocks, S. P. Pope and A. F. Giamei (Pittsburgh, PA: Materials Research Society, 1991), 215-218.

5. M. G. Burke and M. K. Miller, "Precipitation in Alloy 718: A Combined AEM and APFIM Investigation", Proc. Superalloys 718, 625 and Various Derivatives, June 1991, Pittsburgh, PA, ed. E. A. Loria (Warrendale, PA: The Minerals, Metals and Materials Society, 1991), 337-350.

6. B. Sundman, B. Jansson and J-O. Andersson, "The Thermo-Calc Databank System", Calphad, 9 (1985), 153-190.

7. D. Blavette, E. Cadel and B. Deconihout, The Role of the Atom Probe on the Study of Nickel-base Superalloys, Mater. Characterization, 44 (2000), 133-157.

8. R.C. Thomson and M. K. Miller, "Atom Probe Characterisation of High Temperature Materials", Mater. Sci. Technol, 16 (2000), 1199-1206.

9. M. K. Miller, Atom Probe Tomography, (New York, NY: Kluwer Academic/Plenum Press, 2000), 1-216.

10. M. K. Miller, S. S. Babu and M. G. Burke, "Intragranular Precipitation in Alloy 718", Mater. Sci. Eng., A270 (1999), 14-18.

11. M. K. Miller, Proc. Int. Conf. Solid-Solid Phase Transformations PTM'99, May 1999, Kyoto, Japan, ed. M. Koiwa, K. Otsuka and T. Miyazaki (Sendai, Japan: The Japan Institute of Metals, 1999), 73-76.

12. M. K. Miller and S. S. Babu, "Phase Compositions in Alloy 718: A Comparison between APT/APFIM Measurements and Thermodynamic Predictions", Proc. Advanced Technologies for Superalloy Affordability, TMS Annual Meeting, March 12-16, 2000, Nashville, TN, ed. K. M. Chang, S. K. Srivastava, D. U. Furrer and K. R. Bain (Warrendale, PA: The Minerals, Metals and Materials Society, 2000), 63-72. 
13. M. K. Miller, S. S. Babu and M. G. Burke, "Comparison of the Phase Compositions in Alloy 718 Measured by Atom Probe Tomography and Predicted by Thermodynamic Calculations", Mater. Sci. Eng. A. (2001), in press.

14. M. G. Burke and M. K. Miller, "The Application of AEM and APFIM to the Analysis of Precipitation Behavior in Alloy 718", Proc. $2^{\text {nd }}$ Int. Union of Microbeam Analysis Societies, IUMAS 2000, July 9-14, 2000, Kailua-Kona, Hawaii, Inst. Phys. Conf. Ser. No. 165, Symposium 3, ed. D. B. Williams and R. Shimizu, (Bristol, UK and Philadelphia, PA: Institute of Physics Publ., 2000), 161-162.

15. The thermodynamic predictions were computed with the use of the Ni-Fe database, a thermodynamic database for calculation of phase equilibria in multi-component alloys, $\mathrm{N}$. Saunders, ThermoTech Ltd., Surrey Technology Centre, 40 Occam Road, The Surrey Research Park, Guildford, GU2 5YH, UK. 